\title{
Kinematic Test in Multimedia Formats: A Preliminary Validation
}

\author{
Sentot Kusairi ${ }^{1}$, Chanita Helma Wahyu Pangestu ${ }^{1}$, Nurul Hidayat ${ }^{1}$, Ahmad Suryadi ${ }^{2}$ \\ ${ }^{1}$ Universitas Negeri Malang, Indonesia \\ ${ }^{2}$ Universitas Islam Negeri Syarif Hidayatullah Jakarta, Indonesia
}

\begin{abstract}
In physics, computer-based tests have been widely developed, however, the questions are only presented in textual and pictorial representations. We have developed a kinematic test in the multimedia format, which is so called multimedia-based test (MBT). For comparative study purposes, two groups of students were alternately set to take the MBT and paper-based test (PBT). From the statistical analysis, it is revealed that there was no significant difference between the MBT and PBT. Therefore, the MBT can be used for reliable assessment tool. We also found that students were more motivated to work on multimedia format.
\end{abstract}

Keywords - multimedia-based test, kinematics, paper-based test, students' response.

\section{Introduction}

The precipitous development of computer technology, multimedia, and informatics has led to many changes in various aspects of human life, with no exception in the education sector. This is more pronounced in the nowadays' COVID-19 pandemic, where students and teachers have to deal with distance learning using online platforms [1]. Therefore, using a computer for learning and instruction is inevitable, not merely for teaching purposes, but also for assessments.

\section{DOI: 10.18421/TEM104-41}

https://doi.org/10.18421/TEM104-41

Corresponding author: Sentot Kusairi, Department of Physics, Faculty of Mathematics and Natural Sciences, Universitas Negeri Malang, Indonesia. Email: sentot.kusairi.fmipa@um.ac.id

Received: 26 June 2021.

Revised: 01 November 2021.

Accepted: 06 November 2021.

Published: 26 November 2021.

(c) BY-NC-ND (C) 2021 Sentot Kusairi et al; published by UIKTEN. This work is licensed under the Creative Commons Attribution-NonCommercial-NoDerivs 4.0 License.

The article is published with Open Access at www.temjournal.com
According to Shute and Rahimi [2], computer use in assessment is predicted to increase in various learning contexts continuously. International tests such as the Trend in Mathematics and Science Study (TIMSS) and the Programme for International Student Assessment (PISA) have been implemented by using a computer. In Indonesia, the national exams and college entrance tests in recent years have gradually being changed from paper-based to computer-based tests.

Conventional paper-based test (PBT) and modern computer-based test (CBT) assessments have their own advantages and disadvantages. According to Sangmeister [3], compared with the computer-based test, PBT is superior in terms of overall suitability of the item and model fit. In addition, PBT also allows students to directly write on the question paper to solve the problems [4]. However, according to Adanır, Akmatbekova, and Muhametjanova [5], many teachers have difficulty when the exam is done with PBT-mode, especially to give specific feedback for every single student's answer and spend a long correction time. Related to that fact, in recent years, students' competency assessment has begun to switch to CBT. The computer-assisted test is claimed to be the better alternative to replace PBT since it has many advantageous, for instance: effective use of time [6], low production cost [7], direct feedback [8], no distance barrier [9], and powerful instrumental [10]. However, CBT developed has to carefully consider the design and structure of the test [11].

Recent studies have been conducted to compare how students respond when conducting tests with CBT and PBT. Some found that there are no differences in the results of students performing the tests with computer and paper [12] [13] and some others revealed different findings [14] [15]. Meanwhile, there are also judgments that students' learning outcomes measured with CBT and PBT could be the same with a note that the students should always be given multiple reminders during the CBT mode [16]. In other words, there exist inconsistency interpretations to compare the CBT and PBT modes that guarantee the same results.

Along with the technology advances, there are emerging numbers of CBT innovations, one of which 
is the presence of multimedia-based test (MBT). In MBT, instead of just text and images, the problem presented on the computer screen is dynamic and interactive. de Klerk, Veldkamp, and Eggen [17] created a framework of making MBT by combining the theory of test development with the performancebased test to measure the skills of vocational education students. Furthermore, a study conducted by Kuo and $\mathrm{Wu}$ [18] claimed that MBT could be used to measure students' understanding to solve complex science problems. In addition, the dynamic representations in MBT make it more appealing to students and help students even whom with poor understanding to better visualize the problems [10].

On the other side, there are several obstacles to the development and implementation of MBT in the classroom. In the MBT test, students need more time to answer questions due to the repetition effect [14]. In addition, MBT preparation is relatively long when compared to other conventional type tests [19]. The validity and reliability have also been quite serious challenges in MBT implementation [20]. Another challenge is that the empirical evidence regarding the use of multimedia in recording the ability of students is still not widely presented [21]. The MBT implementation is also more complicated when dealing with students who have little experience using a computer at schools [22].

In principle, assessments are used to evaluate students' learning outcomes and determine how close they are to learning objectives. A study conducted by DeBoer et al. [19] in science subjects found that the use of MBT could be effective if designed with conceptual frameworks and meaningful problems so that the students' understanding can be comprehensively recorded. Science learning that deals more with real phenomena should be evaluated with an assessment that presents the phenomena. Considering the challenges above, the MBT format is appropriate when applied to science materials, more importantly physics.

In physics, kinematics is the most fundamental concept to understand. It covers the very basic principle of motion that governs all branches in physics. Once a student acquires proper understanding in kinematics, he will be easier to understand other physical concepts, from vibrations and waves to electrodynamics. Therefore, assessment to measure students' understanding in kinematics is very crucial. Some tests have been developed, e.g., the Halloun-Hestenes Mechanics Diagnostic Test [23], the Mechanics Baseline Test [24], and the other kinds of mechanics test developed. Although these tests are usually presented in PBT format, however, other kinematics tests have also been developed to be accessed by students using a computer with unmoving pictures [25]. As far as the kinematics assessment is concerned, it is commonly found that the questions presented in both PBT and CBT are the same. The only difference is just the use of paper and computers. Therefore, the development of problems set using moving pictures is crucial for assessment. In this present study, crucial research questions relating to the use of MBT and PBT for assessing students' understanding of kinematics are evaluated. This present study aims to evaluate the use of PBT and MBT to assess students' understanding on the kinematics concept.

\section{Methods}

This development research involved 100 high school students and several physics teachers. The stages of research include: (1) preliminary studies, (2) product development, and (3) try out. In the preliminary study, a literature study was conducted to examine the results of research on kinematics graphic difficulties, approaches to overcome difficulties and the recent development of media and games related to the formative assessment. Based on various learning difficulties of kinematics graphs found, the researchers determine and develop learning indicators as a reference to develop isomorphic multiple choice items and other learning materials. Furthermore, for each learning indicator, 3 isomorphic multiple choices of multiple points were developed so that a total of 18 points were produced. The set of learning indicators and items were reviewed by the material experts and a teacher to get suggestions for improvement. After the revision, the test items were tested on conventional high school students. This set of multiple choice items became material for developing formative feedback games.

\subsection{Experimental Sample}

The study involved two groups of students from Madrasah Aliyah Negeri (MAN), an Islamic-based senior high school in Indonesia. Unlike common senior high school, Madrasah Aliyah Negeri has a heavier study load in its curriculum. The MAN students have to also learn extra Islamic subjects. Consequently, MAN students' learning achievement in science subjects, e.g., physics or chemistry, is relatively lower than that of the other schools. In this study, the students were familiar with using a computer at their school. With that, the use of MBT to assess their understanding was not a problem. Prior to the test was performed, the students have learned kinematics, i.e., straight-line motion, a few weeks before. This study involved two classes where the first class consisted of 29 students, while another class consisted of 23 students. Both classes employed PBT and MBT for assessment with different orders. 


\subsection{Experimental Instrument}

We used 20 questions focused on straight-line motion in kinematics. The questions were adapted from previous studies. Table 1 describes the specific conceptual understanding with the corresponding item questions. The questions are presented in PBT and MBT formats, and they were reviewed by experts from physics lecturer and a teacher. The conceptual distribution for each PBT and MBT followed Table 1. The sample questions for PBT (using verbal and graphical representations) and MBT (using animation) are displayed in Table 2. In these tests, students were able to repeatedly read the question texts of play the animations.

Table 1. Item Questions Distribution

\begin{tabular}{|l|c|}
\hline \multicolumn{1}{|c|}{ Concept } & Question Number \\
\hline Distance and Displacement & $1,2,12,17$ \\
\hline Velocity and Acceleration & $3,4,7,8,10,13,16,18$, \\
& 19,20 \\
\hline Kinematics Graph & $5,6,9,11,14,15$ \\
\hline
\end{tabular}

Table 2. Sampel Questions for PBT and MBT. Q Stands for Question

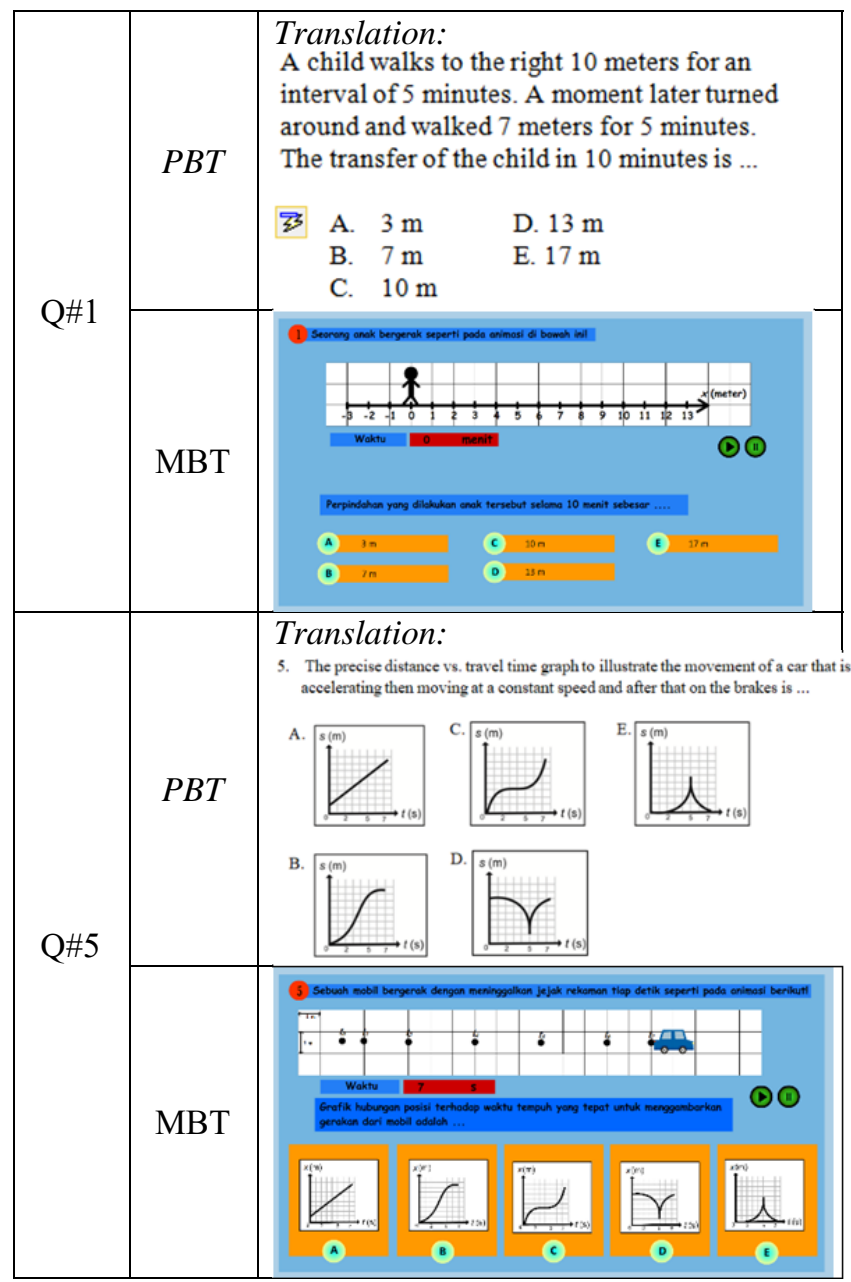

\subsection{Experimental Data}

The data were collected from two groups of MAN students. The first group (Group I) took PBT first before the MBT and the second group (Group II) completed the reverse sequence. The second test was done seven days after the first tests. Once the two test sessions were completed, the students were asked to fill in questionnaires related to their experiences when facing the PBT and MBT.

\subsection{Data Analaysis}

The data were analyzed by means of descriptive statistics and inferential statistics. The mean, standard deviation, maximum score, and minimum student score were used to present the data. A comparison test was conducted using an independent $\mathrm{t}$ test. This test was used to compare students' scores taking the PBT and MBT both during the first session and during the second session of the test. In addition, in order to ensure that there was no effect on the various test series, an independent $t$ test was also carried out between the sample using PBT first then MBT (the first sequence), and the sample using MBT first then PBT (the second sequence).

\section{Results and Discussion}

Table 3 shows the descriptive analysis for both PBT and MBT that were followed by 52 students. The table also includes the mean, maximum, minimum, and standard deviation of the students' scores for each test. As can be seen from Table 3, the statistical data are similar; even the minimum scores are exactly the same. Although the students have learned the chapter before the tests, it is recorded that their mean scores are relatively low, i.e., around 50 . Furthermore, the students' correct percentage for every concept can be seen from Table 4. It is known that the students performed well on distance and displacement concepts but with poor understanding on the kinematics diagram. On the other hand, the students attained medium level of comprehension for the concept of velocity and acceleration.

Based on the sequential order, distance and displacement are the very beginning concepts to be learned by students for the kinematics chapter. In this part, the students' maximum of correct answers reached almost $80 \%$. Oppositely, the students' performances on the other kinematics sub-chapters were relatively low. There was nearly $58 \%$ for velocity and displacement and only $20 \%$ of the correct answer for kinematics graph. 
Table 3. Descriptive Statistic for MBT and PBT

\begin{tabular}{|c|c|c|}
\hline Descriptive statistic & MBT & PBT \\
\hline $\mathrm{N}$ & 52 & 52 \\
\hline Mean & 51.06 & 49.62 \\
\hline Max & 75.00 & 80.00 \\
\hline Min & 25.00 & 25.00 \\
\hline Standard Deviation & 13.37 & 11.62 \\
\hline
\end{tabular}

Table 4. The Distribution of Students' Correct Percentage

\begin{tabular}{|l|c|}
\hline \multicolumn{1}{|c|}{ Concept } & Correct Percentage \\
\hline Distance and Displacement & $78.62 \%$ \\
\hline Velocity and Acceleration & $57.39 \%$ \\
\hline Kinematics Graph & $20.04 \%$ \\
\hline
\end{tabular}

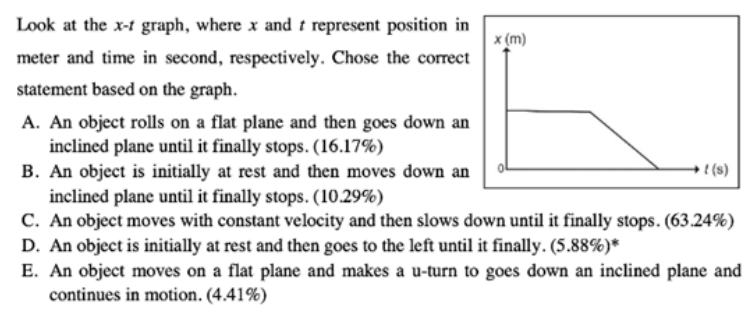

Figure 1. Question on x-t Graph

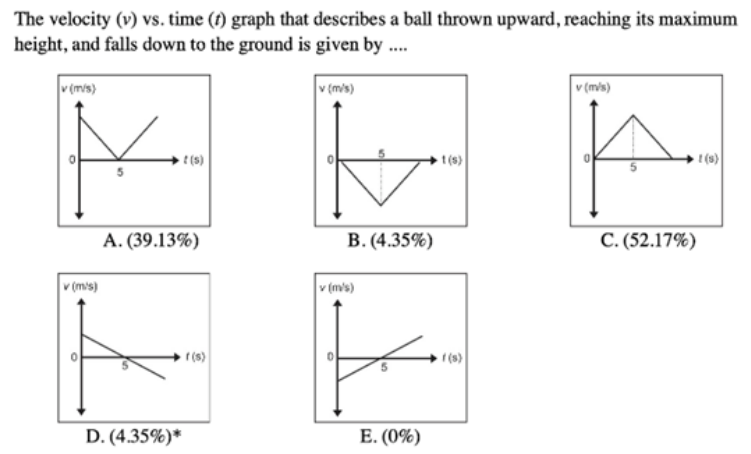

Figure 2. Question on v-t Graph

Figure 1 provides one of the sample questions, which has been translated into English for positiontime $(x-t)$, including the percentage of students' responses for each answer option. The correct answer to that question in option D. To arrive at this correct answer, a student has to be able to read and understand the $x$ - $t$ graph properly. Understanding the meaning of the line of the graph is crucial. That way, the student is able to interpret the graph to physical meaning. Another way to understand this graph is to transfer it to other kinds of representations, such as a table. In this question, only $6 \%$ of the students provided the correct answer. $63 \%$ of the students chose to answer $\mathrm{C}$. The students who picked the choices A and B were only $16 \%$ and $10 \%$, respectively. Lastly, only two students decided option E as their correct answer.

Another difficulty faced by students can be seen in Figure 2. The correct answer for the question in Figure 2 is D. In this case, a student has to understand that when a ball is thrown upward, it experiences a downward gravitational acceleration that makes its' velocity decreases to zero at the highest position. Once that condition is achieved, the ball eventually falls down with the same downward acceleration until it reaches the ground. Therefore, the correct answer is $\mathrm{D}$. In this question, only $4.35 \%$ of the students arrived at either D or B, and none of them chose the option E, as the opposite graph as compared to the option D. More than half of the students' preferred answer C and almost $40 \%$ of them went to option A.

An independent $t$ test was performed to assess if there were differences in the scores of students using PBT and MBT. The results are shown in Table 5. The results of the comparison test showed that there was no substantial difference between the students who used PBT and MBT at both session 1 and session $2(p>0.05)$. In addition, the findings of the study also revealed that there was no significant difference in the scores of students who did PBT first than MBT and those who did MBT first than PBT.

Table 5. Comparison of students' score who used PBT and MBT

\begin{tabular}{|l|c|c|c|c|c|c|}
\hline & $\begin{array}{c}\text { Test } \\
\text { Format }\end{array}$ & N & Mean & SD & $\mathbf{t}$ & $\mathbf{p}$ \\
\hline \multirow{2}{*}{ Session 1 } & PBT & 29 & 44.48 & 8.49 & -1.82 & 0.08 \\
\cline { 2 - 7 } & MBT & 23 & 50.00 & 13.31 & & \\
\hline \multirow{2}{*}{ Session 2 } & PBT & 23 & 56.09 & 11.97 & -1.16 & 0.25 \\
\cline { 2 - 7 } Sequence & MBT & 29 & 51.90 & 13.59 & & \\
\hline & $\begin{array}{c}\text { PBT -> } \\
\text { MBT }\end{array}$ & 58 & 48.19 & 11.84 & -1.20 & 0.05 \\
\cline { 2 - 7 } & $\begin{array}{c}\text { PBT }-> \\
\text { PBT }\end{array}$ & 46 & 53.04 & 12.88 & & \\
\hline
\end{tabular}

Furthermore, the students' responses on the questionnaire items, after taking the MBT and PBT, is depicted in Figure 3. Around 35\% of the students "absolutely agree" that MBT is easier than PBT, and nearly $62 \%$ of them also "agree" on that question (Q1). This trend is similar to the students' opinion on the animations in MBT; the majority of students feel that the animations were exciting (Q2). Exactly the same as in Q2, only 6\% of the students had difficulty with the language (Q3). $21 \%$ of the students stated that the MBT was not suitable for summative, formative, chapter exams, middle and final exams (Q4). 19\% of the students "disagree" that the MBT questions were a lot easier than PBT (Q5). Precisely a quarter of students considered that the animations did not encourage them to figure out the problem (Q6). In addition, Q2 and Q5 are the aspects in which the students put their "absolutely agree" opinion, reaching out $38 \%$. Nearly three quarters of students "agree" that the language in MBT was easy. No students answered "absolutely disagree" for all the questionnaire questions. 
Additionally, the students were also interviewed to capture their opinion regarding the tests. Some of their answers (translated in English) are as follows: (1) "The MBT is easy because we there are moving pictures in it that makes it easy to understand the question," (2) “Taking MBT is not boring," (3) “The pictures and animations are interesting, but not the audio," and (4) “In my opinion, doing test with animation is enjoyful"

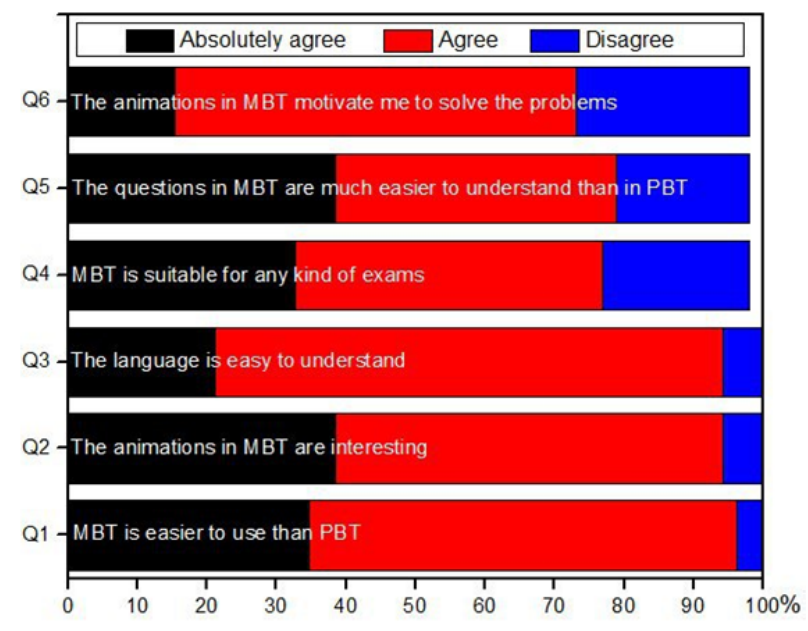

Figure 3. Students' Responses on The Questionnaire on Using PBT and MBT. Q stands for Question

The study is aimed to investigate the suitability of MBT and PBT for kinematics assessment. From the statistical analyses, it is revealed that both MBT and PBT can be used for effective assessments. The similarity of the students' scores when taking the MBT and PBT indicated that both assessment tools have the same compatibility to measure students' competency. Technically, in MBT, students can see the visualization of the problems through animation, which is not available in PBT [26]. Therefore, the kinematics-related phenomena described in the questions can be more easily understood by the students when they face MBT. However, understanding the questions alone is not enough to make students correctly answer the questions. They have to also understand the concepts well, otherwise, they are not able to arrive at the correct option for both MTB and PBT [27]. The students understand the concepts of distance and displacement and therefore obtain a good score. However, they acquire adequate and poor understanding on velocity, acceleration, and kinematics graph. Therefore, in general, the students' score for these kinematics tests are relatively low. It is believed that the students felt more difficult when the concepts were more complicated. Since their understanding on the velocity and accelerations was just in the upper medium, then they had difficulty to correctly answer the kinematics diagram questions. This is in line with other reports that kinematics graph is more difficult to be understood by students [28] [ 29].

From the questionnaire results, it is known that students put more interest in taking MBT than PBT. As millennials, they are now more familiar with computer and multimedia-based learning platforms that provide many interactive features. Many learning resources they find on their computer. Students nowadays prefer to use e-books than real textbooks and enjoy experiencing computer-based than paper-based tests. According to Hao [30], students emotionally tend to be more positive on MBT when they have a choice of the learning or assessment platforms. In addition, when taking the exam using multimedia, students are able to use play and pause buttons, which is not available in the PBT, to understand the phenomena in the question [31].

This study recommends that MBT can be used as an alternative to the PBT. The MBT is proposed not only because it represents similar results as compared to PBT, but it is also considered as one of the global campaign [32] in reducing the use of paper. With MBT, all that is required is the creativity of teachers and the infrastructure of technology. Teachers and educational practitioners should consider using MBT as a method of question presentation that is not monotonous. In addition, the students nowadays are more familiar with the use of multi-media technology for their learning experiences. The PBT is therefore believed to meet the need of the $21^{\text {st }}$ century students' need.

Since that the MBT and PBT provide the same results for assessment and the students are more interested in using MBT, then we suggest that this kind of MBT can be used for today and future assessment to replace the PBT. With MBT, many advantages can be obtained, not merely in terms of effectivity, but also the efficiency. The feedback feature in the MBT makes it possible as a means for either formative or summative assessments). With this result, the MBT for other physics chapters can also be developed. However, unlike PBT, we cannot evaluate students' answer in detail in PBT. We can only see the final answer, which is probably not based on the complete analysis or calculation, but from the student's guess. For the best practice, there is a chance to develop a multimedia-based assessment that also captures students' analysis before choosing the final answer for every question.

\section{Conclusion}

The kinematics tests designed in multimedia format (MBT) can produce results that are relatively the same as kinematics tests in paper format (PBT). This study also shows that MBT is more preferred by students and is able to help them better understand the purpose of the problem. Therefore, this kinematics test can be used for both formative and summative 
purposes. In terms of kinematics conceptual understanding, the MAN students, in this study, had a good performance on the distance and displacement concepts, adequate understanding on velocity and acceleration, and poor competency on kinematics graphs problems.

\section{References}

[1]. Mailizar, Almanthari, A., Maulina, S., \& Bruce, S. (2020). Secondary School Mathematics Teachers' Views on E-learning Implementation Barriers during the COVID-19 Pandemic: The Case of Indonesia. Eurasia Journal of Mathematics, Science and Technology Education, 16(7), em1860. https://doi.org/10.29333/ejmste/8240

[2]. Shute, V. J., \& Rahimi, S. (2017). Review of computer-based assessment for learning in elementary and secondary education. Journal of Computer Assisted Learning, 33(1), 1-19.

https://doi.org/10.1111/jcal.12172

[3]. Sangmeister, J. (2017). Commercial competence: Comparing test results of paper-and-pencil versus computer-based assessments. Empirical Research in Vocational Education and Training, 9(1), 1-19. https://doi.org/10.1186/s40461-017-0047-2

[4]. Prisacari, A. A., \& Danielson, J. (2017). Computerbased versus paper-based testing: Investigating testing mode with cognitive load and scratch paper use. Computers in Human Behavior, 77, 1-10. https://doi.org/10.1016/j.chb.2017.07.044

[5]. Adanır, G. A., Akmatbekova, A., \& Muhametjanova, G. (2020). Longitudinal study of Kyrgyz students' general physics course performance in paper-based versus online-based tests. Education and Information Technologies, 25(5), 4197-4210.

https://doi.org/10.1007/s10639-020-10175-7

[6]. Lindner, M. A., Eitel, A., Strobel, B., \& Köller, O. (2017). Identifying processes underlying the multimedia effect in testing: An eye-movement analysis. Learning and instruction, 47, 91-102. https://doi.org/10.1016/j.learninstruc.2016.10.007

[7]. Terzis, V., \& Economides, A. A. (2011). Computer based assessment: Gender differences in perceptions and acceptance. Computers in human behavior, 27(6), 2108-2122. https://doi.org/10.1016/j.chb.2011.06.005

[8]. KUSAIRI, S., ALFAD, H., \& ZULAIKAH, S. (2017). Development of web-based intelligent tutoring (iTutor) to help students learn fluid statics. Journal of Turkish Science Education, 14(2), 1-11. https://doi.org/10.12973/tused.10194a

[9]. Krasnova, L., \& Shurygin, V. (2019). Blended Learning of Physics in the Context of the Professional Development of Teachers. International Journal of Emerging Technologies in Learning (iJET), 14(23), 17-32. https://doi.org/10.3991/ijet.v14i23.11084

[10]. Lin, J. W. (2016). Development and evaluation of the diagnostic power for a computer-based two-tier assessment. Journal of Science Education and Technology, 25(3), 497-511.

https://doi.org/10.1007/s10956-016-9609-5
[11]. Solihati, N., \& Mulyono, H. (2018). Designing and evaluating the use of smartphones to facilitate online testing in second-language teacher education (SLTE): An auto-ethnographic study. International Journal of Emerging Technologies in Learning (iJET), 13(1), 124-137. https://doi.org/10.3991/ijet.v13i01.7683

[12]. Krille, C., Wuttke, E., \& Seifried, J. (2017). Mode effects in correcting students' errors: a comparison of computer-based and paper-pencil tests. In Professional Error Competence of Preservice Teachers (pp. 47-74). Springer, Cham. https://doi.org/10.1007/978-3-319-52649-2 4

[13]. Ebrahimi, M., Toroujeni, S. H., \& Shahbazi, V. (2019). Score Equivalence, Gender Difference, and Testing Mode Preference in a Comparative Study between Computer-Based Testing and Paper-Based Testing. International Journal of Emerging Technologies in Learning (iJET), 14(7), 128-143. https://doi.org/10.3991/ijet.v14i07.10175

[14]. Dindar, M., Yurdakul, I. K., \& Dönmez, F. I. (2013). Multimedia in test items: Animated questions vs. static graphics questions. Procedia-Social and Behavioral Sciences, 106, 1876-1882. https://doi.org/10.1016/j.sbspro.2013.12.213

[15]. Nguyen, Q., Rienties, B., Toetenel, L., Ferguson, R., \& Whitelock, D. (2017). Examining the designs of computer-based assessment and its impact on student engagement, satisfaction, and pass rates. Computers in Human Behavior, 76, 703-714. https://doi.org/10.1016/j.chb.2017.03.028

[16]. Nissen, J. M., Jariwala, M., Close, E. W., \& Van Dusen, B. (2018). Participation and performance on paper-and computer-based low-stakes assessments. International journal of STEM education, 5(1), 1-17. https://doi.org/10.1186/s40594-018-0117-4

[17]. de Klerk, S., Veldkamp, B. P., \& Eggen, T. J. (2018). A framework for designing and developing multimedia-based performance assessment in vocational education. Educational technology research and development, 66(1), 147-171. https://doi.org/10.1007/s11423-017-9559-5

[18]. Kuo, C. Y., \& Wu, H. K. (2013). Toward an integrated model for designing assessment systems: An analysis of the current status of computer-based assessments in science. Computers \& education, 68, 388-403.

https://doi.org/10.1016/j.compedu.2013.06.002

[19]. DeBoer, G. E., Quellmalz, E. S., Davenport, J. L., Timms, M. J., Herrmann-Abell, C. F., Buckley, B. C., ... \& Flanagan, J. C. (2014). Comparing three online testing modalities: Using static, active, and interactive online testing modalities to assess middle school students' understanding of fundamental ideas and use of inquiry skills related to ecosystems. Journal of Research in Science Teaching, 51(4), 523-554. https://doi.org/10.1002/tea.21145

[20]. Oostrom, J. K., Born, M. P., Serlie, A. W., \& van der Molen, H. T. (2010). Webcam testing: Validation of an innovative open-ended multimedia test. European Journal of Work and Organizational Psychology, 19(5), 532-550. https://doi.org/10.1080/13594320903000005 
[21]. Davenport, J. L., \& Quellmalz, E. S. (2017). Assessing science inquiry and reasoning using dynamic visualizations and interactive simulations. In Learning from Dynamic Visualization (pp. 203232). Springer, Cham. https://doi.org/10.1007/978-3-319-56204-9 9

[22]. Kühl, T., Navratil, S. D., \& Münzer, S. (2018). Animations and static pictures: the influence of prompting and time of testing. Learning and Instruction, 58, 201-209. https://doi.org/10.1016/j.learninstruc.2018.07.006

[23]. Halloun, I. A., \& Hestenes, D. (1985). The initial knowledge state of college physics students. American journal of Physics, 53(11), 10431055. https://doi.org/10.1119/1.14030

[24]. Hestenes, D., \& Wells, M. (1992). A mechanics baseline test. The physics teacher, 30(3), 159-166. https://doi.org/10.1119/1.2343498

[25]. Araujo, I. S., Veit, E. A., \& Moreira, M. A. (2008). Physics students' performance using computational modelling activities to improve kinematics graphs interpretation. Computers \& Education, 50(4), 11281140. https://doi.org/10.1016/j.compedu.2006.11.004

[26]. Lindner, M. A., Eitel, A., Barenthien, J., \& Köller, O. (2021). An integrative study on learning and testing with multimedia: Effects on students' performance and metacognition. Learning and Instruction, 71, 101100. https://doi.org/10.1016/j.learninstruc.2018.01.002
[27]. Klein, P., Müller, A., \& Kuhn, J. (2017). Assessment of representational competence in kinematics. Physical Review Physics Education Research, 13(1), 010132. https://doi.org/10.1103/PhysRevPhysEducRes.13.010 $\underline{132}$

[28]. Planinic, M., Milin-Sipus, Z., Katic, H., Susac, A., \& Ivanjek, L. (2012). Comparison of student understanding of line graph slope in physics and mathematics. International journal of science and mathematics education, 10(6), 1393-1414. https://doi.org/10.1007/s10763-012-9344-1

[29]. Zakaria, N., Phang, F., \& Pusppanathan, J. (2019). Physics on the Go: A Mobile Computer-Based Physics Laboratory for Learning Forces and Motion. International Journal of Emerging Technologies in Learning (iJET), 14(24), 167-183. https://doi.org/10.3991/ijet.v14i24.12063

[30]. Hao, Y. (2010). Does multimedia help students answer test items?. Computers in Human Behavior, 26(5), 1149-1157. https://doi.org/10.1016/j.chb.2010.03.021

[31]. Colbran, S., Gilding, A., \& Colbran, S. (2017). Animation and multiple-choice questions as a formative feedback tool for legal education. The Law Teacher, 51(3), 249-273. https://doi.org/10.1080/03069400.2016.1162077

[32]. Meishar-Tal, H., \& Shonfeld, M. (2019). Students' writing and reading preferences in a paperless classroom. Interactive Learning Environments, 27(7), 908-918. https://doi.org/10.1080/10494820.2018.1504306 